\title{
Lethal femoral-facial syndrome: a case with unusual manifestations
}

\author{
Y Gillerot, C Fourneau, T Willems, L Van Maldergem
}

\begin{abstract}
The femoral-facial syndrome is a very rare syndrome of uncertain inheritance comprising hypoplastic femora, microretrognathia, and a peculiar facies. We report an additional observation detected by ultrasound at 25 weeks and diagnosed at birth. In addition to the malformations usually described in this syndrome, there were heterotopias of the brain, partial agenesis of the corpus callosum, bilobed lungs, intestinal malrotation, and vertebral segmentation defects. (F Med Genet 1997;34:518-519)
\end{abstract}

Keywords: femoral-facial syndrome; prenatal diagnosis; Pierre-Robin sequence; corpus callosum

First described by Daentl et al in 1975, the femoral-facial syndrome, or FFS, ${ }^{2}$ was initially called femoral hypoplasia-unusual facies syndrome. When the full syndrome is observed, it comprises Pierre-Robin sequence, facial dysmorphism, and femoral hypoplasia. Subsequently 19 observations have been published and most are female. However, there is clinical heterogeneity. In this report we present a severe and lethal type with some unreported findings.

\section{Case report}

The proband was born to unrelated, healthy, young parents originating from southern Belgium. The 24 year primigravida was treated with Ketotifenum (Zaditen (B) for chronic bronchial asthma. Clinical examination of the parents was normal, including normal extremities and absence of cleft palate. The first trimester of pregnancy was uneventful, except for excessive weight gain. Fetal movements were said to be normal. An oral glucose tolerance test was normal and glycosylated haemoglobin was within the normal range $(4.96 \%)$. At 26 weeks, a routine ultrasound examination disclosed bilateral shortening of the femora, which was confirmed at 27 weeks. The right femur was $37 \mathrm{~mm}$ and the left $38 \mathrm{~mm}$ (50th centile for 21 weeks). At 31 weeks a male baby was delivered after premature rupture of the membranes. He died four hours after birth and necropsy was performed within 24 hours.

\section{PATHOLOGICAL FINDINGS}

This newborn male (fig 1) had growth parameters within the normal range; his weight was $1710 \mathrm{~g}$ (60th centile), head circumference 31.5 $\mathrm{cm}$ (60th centile), and crown-rump length 29 $\mathrm{cm}(\mathrm{M}=27.4)$. Foot length was $6.4 \mathrm{~cm}$. The cranial vault was bulging, the palpebral fissures

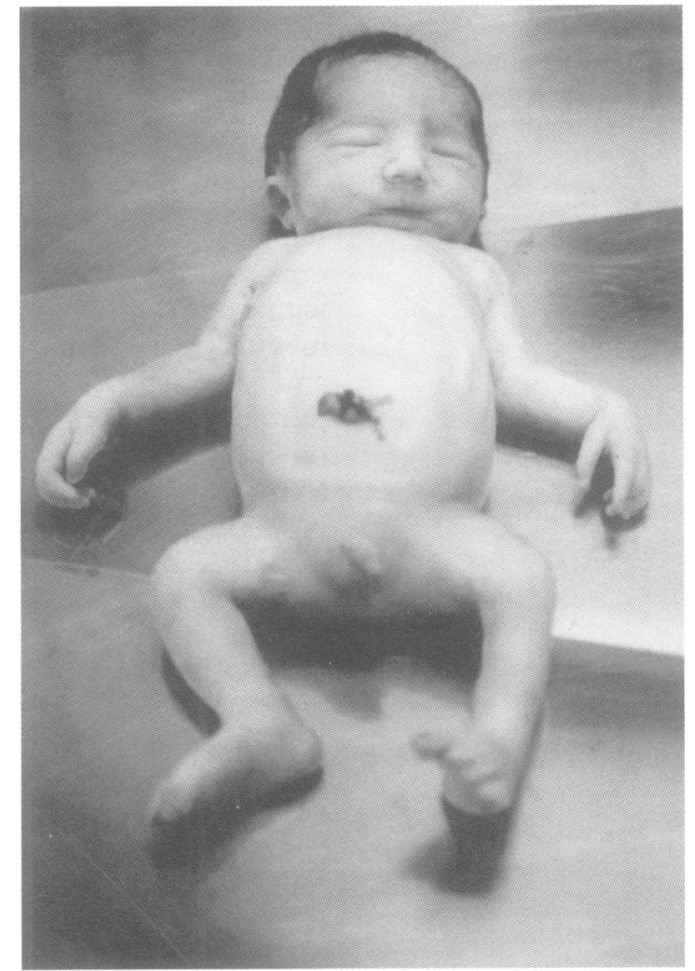

Figure 1 The proband: general view. (Photographs reproduced with permission.)

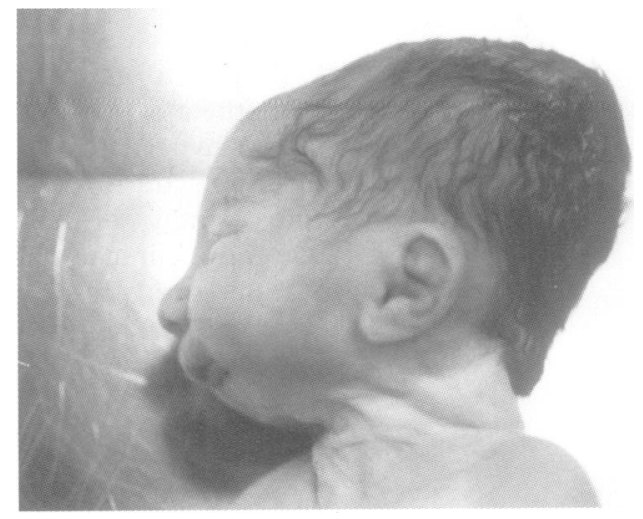

Figure 2 Note the microretrognathia on the frontal facial view.

were downward slanting, the mouth was small and downturned, and complete Pierre-Robin sequence was observed with cleft palate, microretrognathia, and glossoptosis (fig 2). The forearm muscles appeared hypertrophic and distal arthrogryposis with camptodactyly of the third and fourth fingers was present. The lower limbs showed shortening and bowing of their proximal segments.

Brain weight was $212 \mathrm{~g}(\mathrm{M}=214, \mathrm{SD} 64.2)$; in section there was striking dilatation of the lateral ventricles particularly in the posterior 


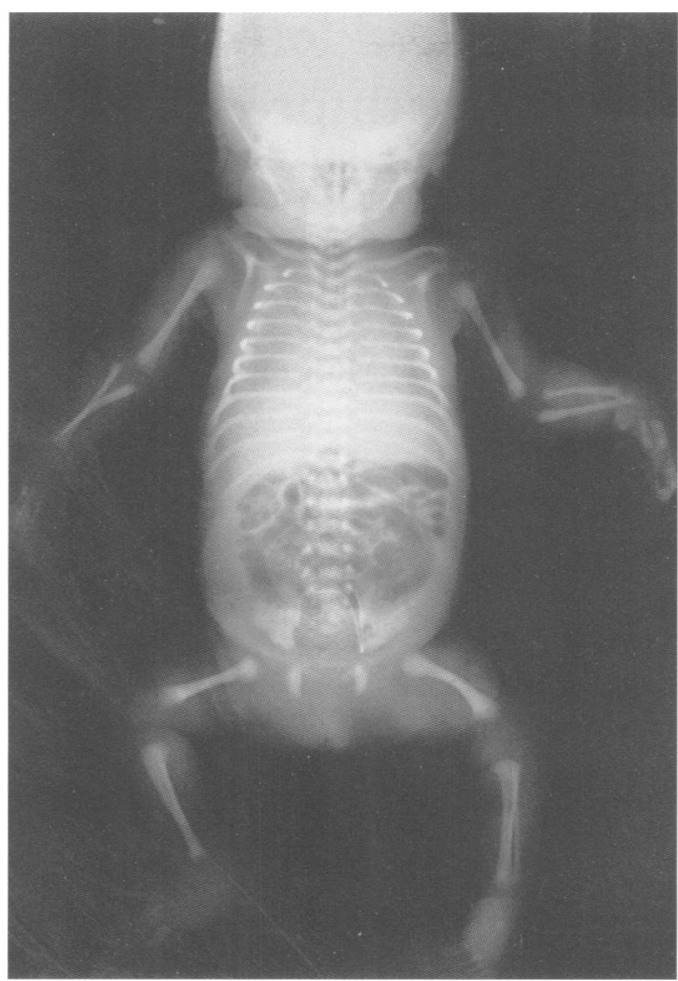

Figure 3 Radiograph showing bowing and shortening of the femora and sacral hemivertebrae.

part. On histology, the external granular layer appeared irregular and was protruding into the molecular layer. In addition, a neuronal migration defect with a number of heterotopias was observed. There was also partial posterior agenesis of the corpus callosum. The right lung was divided into two lobes only. Incomplete rotation of the gut resulting in a medially placed appendix was also noted. The other organs were unremarkable.

Chromosome analysis showed a normal $46, \mathrm{XY}$ karyotype on peripheral lymphocytes and skin fibroblasts.

\section{RADIOLOGICAL FINDINGS}

Microretrognathia was confirmed on a postmortem radiograph (fig 3 ). Shortening and bowing of the femora were seen. The right ulnar head was dislocated and hemivertebrae were observed at $\mathrm{S} 2$.

\section{Discussion}

The severity and clinical expression of FFS appears to be variable when examining the published cases. Burn et al suggested, on the basis of 13 observations, subdividing this syndrome into two groups, according to the presence or absence of facial dysmorphism. The former or "true" FFS is itself composed of three groups: those cases secondary to fetal constraint, those resulting from maternal diabetes, and those of unknown origin. The hereditary nature of the syndrome has only been suggested in two instances. ${ }^{24}$ Regarding our observation, the hypothesis of fetal constraint is unlikely, amniotic fluid being abundant on serial ultrasound examination. However, the CNS abnormalities and the camptodactyly would be compatible with the so-called fetal hypokinesia sequence. Maternal diabetes has been recognised as a causative agent in more than $20 \%$ of the reported cases of FFS. Of note is the sacral hemivertebra that can occur in the classical caudal regression sequence, which can be observed in infants born to diabetic mothers and was present in our case. However, diabetes was excluded by OGTT during pregnancy. Ketotifenum, like other broncholytic drugs, is often used during pregnancy and has not previously been recognised as a teratogenic agent.

A similar set of malformations can be observed in other multiple malformation syndromes. Campomelic syndrome has a somewhat different skeletal dysplasia and facial dysmorphism and is invariably associated with dwarfism. Smith-Lemli-Opitz syndrome type II is associated with Pierre-Robin sequence, polydactyly, lung segmentation defects, and hypotonia, ${ }^{5}$ but the facial dysmorphism is quite different and syndactyly of the second and third toes is nearly constant. The Char syndrome ${ }^{6}$ also shows some similarities, as does VerlooveVanhoorick syndrome. ${ }^{7}$ However, some specific malformations of the latter (rhizomelia of the lower and upper limbs, cardiac and renal defects, absent auditory canal, oligodactyly) were absent in our patient. Finally, we have no indication (family history, clinical examination of the parents) of a specific mode of inheritance. However, with respect to similarities to conditions like campomelic dysplasia, which have been recently shown to occur as a consequence of dominant neomutational events, this mode of inheritance is an attractive hypothesis.

In conclusion, our observation confirms, together with those of Robinow et al and Tadmor $e t a l,{ }^{8}$ the feasibility of prenatal diagnosis of this condition, based on ultrasound visualisation of shortened, bowed femora in association with microretrognathia. This can theoretically be achieved as early as the 18th week of gestation. In addition, we suggest that CNS abnormalities, including neuronal migration defects, enlargement of the lateral ventricles, and partial agenesis of the corpus callosum, as well as vertebral segmentation defects are additional components of the syndrome.

1 Daentl DL, Smith DW, Scott CI, Hall BD, Gooding CA Femoral hypoplasia-unusual facies syndrome. $\mathcal{f}$ Pediatr

2 Robinow M, Sonek J, Buttino L, Veghte A. Femoral facial syndrome. Prenatal diagnosis - autosomal dominant inher-

3 Burn J, Winter RM, Baraitser M, Hall CM, Fixsen J. The femoral hypoplasia-unusual facies syndrome. $\mathcal{F}$ Med Genet 1984;21:331-40.

4 Lampert RP. Dominant inheritance of femoral hypoplasiaunusual facies syndrome. Clin Genet 1980;17:255-8.

5 Donnai D, Young ID, Owen WG, Clark SA, Miller PFW, Knox WF. The lethal multiple congenital anomaly syndrome of polydactyly, sex reversal, renal hypoplasia and unilobar lungs. $\mathcal{F}$ Med Genet 1986;23:64-71.

6 Char F, Readinger RI, McConnell JR, McCoy JR. A new(?) $\mathrm{X}$-linked connective tissue disorder with joint hyperextensibility, mild cutis laxa, skeletal anomalies and idiopathic sibility, mild cutis laxa, skeletal anomalies and idiopathic Center $1987 ; 6: 174-7$

7 Verloove-Vanhoorick SP, Brubbakk AM, Ruys JH. Extensive congenital malformations in two siblings. Maternal precongenital malformations in two siblings. Maternal pre-
diabetes or a new syndrome? Acta Paediatr Scand 1981;70: 767-9.

8 Tadmor OP, Hammermann C, Rabinowitz R, et al. Femoral hypoplasia-unusual facies syndrome: prenatal ultrasonographic observations. Fetal Diagn Ther 1993;8:279-84.
gial 